\title{
Ethics issues identified by obstetrics and gynecology learners
}

\author{
Rachel Mejia, DO, ${ }^{1}$ Laura Shinkunas, BA, ${ }^{2}$ Ginny Ryan, MD, MA ${ }^{1}$
}

Keywords: Ethics, medical, obstetrics, gynecology

\section{Objective:}

This study evaluated a specific ethics and professionalism curriculum whereby medical students and residents provided a written assessment on various ethical issues encountered during their Ob/Gyn rotations. Our goal with this study was to retrospectively evaluate the content of reflections written by medical students and resident physicians and compare content and issues identified by each learner level. Our ultimate goal is to use these data to refine and improve the ethics and professionalism curriculum for Ob/Gyn medical learners.

${ }^{1}$ Department of Obstetrics and Gynecology, Carver College of Medicine, University of lowa Hospitals and Clinics, lowa City, IA, 522422

${ }^{2}$ Department of Medical Ethics, University of lowa Hospitals and Clinics, lowa City, IA, 52242

\section{Methods:}

An ethics curriculum was implemented for Ob/Gyn medical students and residents, which included written and group discussion components. A total of 181 Case Observation Assessments (COAs) were submitted - 127 COAs from 127 medical students and 54 COAs from 18 residents. The COAs were d-identified and coded using basic qualitative content analysis. The COAs were coded using seven different ethical and professional domains. Coded text was entered into NVivo 8 for data management purposes, and basic quantitative summary statistics for these codes were generated.

\section{Results:}

The mean word count in the medical students' COAs was 653 as compared to 521 in the residents' COAs ( $p$ value of 0.0001 ). Residents were significantly more likely to write about issues in Obstetrics, whereas students were significantly more likely than residents to discuss Oncology issues. Within the seven domains, medical students and

Please cite this abstract as: Mejia R, Shinkunas L, Ryan G. Ethics issues identified by obstetrics and gynecology learners. Proc Obstet Gynecol. 2013;3(3):Article 8 [ 2 p.]. Available from: http://ir.uiowa.edu/pog/. Free full text article.

Corresponding author: Rachel Mejia, Department of Obstetrics and Gynecology, University of lowa, 200 Hawkins Drive, lowa City, IA 42242. rachel-mejia@uiowa.edu

This is an Open Access article distributed under the terms of the Creative Commons Attribution 3.0 Unported License (http://creativecommons.org/licenses/by/3.0), which permits unrestricted use, distribution, and reproduction in any medium, provided the original work is properly cited. 
residents only significantly differed on the frequency of citing communication issues. The domains were divided into 42 subcategories in which all learners frequently cited inadequate communication, fulfillment of fiduciary responsibility by provider, and conflicting responsibilities to mother versus fetus/baby. Medical students explicitly identified sources of ethical value more frequently than residents. Learners provided an assessment (agree or disagree) of the clinical situation. Residents disagreed more often than medical students.

\section{Conclusion:}

This novel curriculum gives Ob/Gyn learners an opportunity to voice concerns through written report and group discussion. This exploratory study identifies and incorporates the ethical and professional issues that arose for learners in the field of Ob/Gyn and the differences that exist between medical student and resident learners. Our findings will help Obstetrics and Gynecology educators identify specific ethical issues within the field of Ob/Gyn that may need more discussion for both medical students and residents.

Presented at "Advancing Women's Health at Home and Around the World," the University of lowa Obstetrics and Gynecology Postgraduate conference, 26 October 2012, hotelVetro \& Conference Center, lowa City, lowa 52240. 